\title{
ALGUNOS PROYECTOS DE MEJORA PARA EL MADRID DE CARLOS III
}

\section{Enrique Martínez Ruiz}

La segunda mitad del siglo XVIII se viene considerando como el periodo de culminación del "reformismo borbónico" espaffol, sobre todo el reinado de Carlos III. A la indudable actividad gubernamental existente sobre el particular, hay que añadir el ambiente favorable generado en un espectro social, más o menos ámplio y más o menos próximo a la Administración, que se sitúa en diversos niveles de la sociedad y cuyo rasgo común más acusado, tal vez, es la posesión de un nivel educacional y cultural de cierta altura. Ello les permite no solo conocer las iniciativas gubernamentales con más detalle que la mayoría de la población, sino también analizarlas en función de su utilidad y, lo que es más importante para nosotros ahora, ver la forma en que ellos mismos pueden contribuir a mejorar esas iniciativas superiores o aportar ideas nuevas sobre ramos en los que la Administración esta más pasiva o desacertada, según su criterio; "colaboración" con el gobierno que responde a motivaciones diversas y que se suele manifestar en la elevación a las instancias supremas de planes y proyectos variados, nacidos los más de el deseo de sus autores de lograr un puesto retribuido por el Estado como premio al contenido del proyecto o a su interés por los asuntos públicos. A veces, esa colaboración es provocada por la convocatoria de unos premios para las mejores ideas aplicables a ciertas cuestiones o problemas. Como el gobierno mantedrá siempre una receptividad propicia a estos proyectos, los planes y propuestas más diversas no faltará sobre la mesa de ministros y consejeros.

Según lo que se desprende de la documentación que hemos manejado y dada esa permisibilidad gubernamental, los años setenta y ochenta van a registrar una avalancha de escritos al rey o a sus ministros con pana- 
céas y remedios de muy diversa índole y diferente alcance, escritos que ya habían empezado a enviarse antes y afluirían también después de estas décadas, elaborados incluso a ambos lados de los Pirinéos.

Los hay para todos los gustos, pues por su contenido pueden clasificarse como utópicos, visionarios, inmaduros, irrealizables, posibles, probables ... e ineficaces. En realidad, ninguno de ellos en la forma que fue presentado, llegó a realizarse. Es más no hemos encontrado ninguna noticia que testimonie la declaración de vencedores en alguns de esos certámenes ni la entrega de alguno de los premios, lo que cuando menos parece evidenciar o una desestimación de los planes presentados o una falta de eco en la convocatoria o bien su escasa transcendencia pública, de modo que si el premio se entregaba, no era algo noticiable que mereciera publicidad. Por eso, pensamos que, en conjunto, esas convocatorias de premios no eran más que globos sondas, mediante los cuales el gobierno o el convocante recibía una información muy variada de la que, quizás, algo pudiera aprovechar.

Ejemplos ilustrativos de los planes ideados en aquellas fechas pueden ser incluidos en la selección siguiente: el que presenta D. Félix de Motes y de González sobre "los medios de desterrar la mendicidad" (escrito en latín, nada menos); el de Marcos Passarin "para recoger y criar los Nifios Expósitos en el hospital Real de Santiago de Galicia" (proyecto muy madrugador, pues data de 1758); el de D. Manuel Pérez de Rozas, que lleva por título "Reflexiones políticas pa. el mejor gobierno de las Probincias, facilidad y comodidad de sus Abastos, Contribuciones: comercio de grano, etc." (esta fechado el 31 de agosto de 1789); en 1796 sale a la luz el de D. José Grifol Caballero, sargento de Granaderos, "sobre tierras baldías y rea lengas" (tal vez más que otra cosa, lo que el sargento buscara fuera eludir responsabilidades, pues "habiendose venido sin lic. de sus Gefes de la Plaza de Cádiz para hacer dho. Proyecto pide se manifieste a sus Gefes pa. no incurrir en las leyes de Deserción"). A fines de 1788 está en pleno debate un Proyecto sobre la reforma de los trajes femininos y la implantación de un traje nacional, respecto al que la opinión toma partido decidido en pro o en contra; a favor lo hace, en otras muchas, Da. María Martínez de Revuelta, que envia desde Málaga unas consideraciones sobre la viabilidade del proyecto; en el bando contrario, no menos nutrido, estan las "Señoras Socias Matritenses". A fines de febrero la pugna continuaba.

La mendicidad - o mejor, su corrección - es el objetivo del proyecto enviado desde Córdoba el 17 de junio de 1779 por D. Miguel Ximénez Navarro; de los más tardios son los de D. José García de Paredes, uno sobre el establecimiento de Contadurías Públicas, Autos, Testimonios y Partidas Sacramentales (es el más voluminoso y completo de los dos ) y 
otro a cerca de la "seguridad pública en la Nación". "De Correos y correspondencia gral. del Reyno" trata el que presenta el licenciado D. Manuel Romero del Alamo, que lo remite desde Val de Oliva (9 de enero de 1785). D. Felipe Medrano, Cabalero de Santiago, remite otro plan sobre limpieza de aguas sucias, escombros, barreduras y manera de empedrar, muy ilustrativo de la visión que se tenia de estas cuestiones en la époa. ${ }^{1}$

En fin, los ejemplos podían multiplicarse, pero como muestra de su variedad nos parece suficiente. Nosotros nos vamos a detener en alguns de los proyectos presentados durante el reinado de Carlos III que tienen como elemento común su preocupación por cuestiones ciudadanas, relativas a Madrid. Constituyen una especie de muestrario en el que quedan de relieve, en unos casos, hechos que tienen una especial incidencia o significación en Madrid y en otros, vemos planteamientos más ámbiciosos que afectan a toda "gran ciudad", cuyo pulso y ritmo llamaba la atención de los gobiernos por serles necesario afrontar las nuevas exigencias y problemas originados en los grandes centros urbanos; $y$ no faltan los que atienden facetas de la política que ha puesto en marcha el gobierno, por lo que se sitúan en las coordenadas de acción del poder.

Como pórtico introductorio dejaremos testimonio de un peligro que frecuentemente sacudía la vida madrileña y que preocupaba seriamente a las autoridades. Nos referimos a los incendios, mal que Madrid, padecía con sempiterna constancia y que por los materiales empleados en la construcción de las casas y la estrechez de no pocas calles, resultaban especialmente voraces y dramáticos. En el verano de 1773. Aranda es el eje en torno al que gira una serie de iniciativas que culminan con la divisón de Madrid en cuatro cuarteles, en cada uno de los cuales habría una especie de reten, debidamente equipado para acudir prontamente a la extinción del incendio que se presentase y no tener que recurrir a los procedimientos habituale: "Es bien notorio que la maior precaución que antes se conocía, era la de maior destrozo, por que a fin de Yslar el volcán, y dejarlo a que por sí mismo se consumiese, se sacrificavan las casas inmediatas de ambos costados y de la espalda, cortando sus tejados y pavimentos". una rápida intervención se juzgaba imprescindible para tener éxito y reducir al mínimo las pérdidas, dada la forma de construir de la época: "los riesgos en Madrid pueden ser frecuentes y las quemas de mucha consequencia, pues el estilo doméstico de los Braseros, y esteras y la construcción de los edificios con la armazon quantiosa de madera con que se lebantan, son causas de repentinos fuegos y de un estrago que trasciende a las Casas imediatas, y exponen hasta manzanas enteras de ellas". ${ }^{2}$ 
Al parecer no se llegó muy lejos en este terreno, pues a fines de siglo todavía hay ofertas para que establezca en Madrid un "cuerpo de bomberos" $^{3}$

\section{Plan de D. Miguel Ruano}

El proyecto presentado por D. Miguel Ruano es el más extenso de todos y para nosotros resulta especialmente, porque si bien se refiere a Madrid de manera específica, en su contenido frecuentemente se alude a la gran ciudad o a la gran urbe, lo que puede evidenciar semejanza de problemas en los grandes núcleos urbanos y toma de conciencia del problemas en los grandes núcleos urbanos y toma de con ciencia del problema que estos empiezan a constiuir.

El plan en cuestión está redactado a raiz de la publicación de la Real Cédula de 17 de marzo de 1782, creadora de la Superintendencia General de Policia, cuyo contenido saluda el autor "lleno de júbilo". Su título da idea cabal de la alta meta que se propone: "Medio de evitar en la Corte los Robos, Muertes, y Bullicios".

Letrado de profesión, D. Miguel demuestra ámplios conocimientos, pues anota profusamente su texto con referencias latinas, tanto literarias como históricas y jurídicas. El voluminoso proyecto se inicia en un tono teórico-doctrinal, en el que el autor se posiciona ante la vida en comunidad y sus manifestaciones. Como punto de partida para la glosa de este proyecto ${ }^{4}$, nos puede servir el siguiente párrafo: "El mismo Señor que ha querido inspirar al hombre esta qualidad sociable, dejándoles a todos en su corazón mui poco arbitrio para nos vivir congregados es quien ha creado igualmente el orden, y la consonancia de los que han de vivir en comunidad, o, unidos". Extremos sobre los que se extiende después con detenimiento, desarrollando su contenido, para conluir confesando su objetivo: "En primer lugar se manifestará sucintamente el dano; $\mathrm{Y}$ en segundo se expressará el remedio que es más adecuado: Primero se hará ver, que el mal de la oziosidad, de los robos, tumultos, y otros atentados nace de la multitud inordinada de la confusión de la Corte: Y después se esplicara la medicina del orden, que es el más capaz de sanar todos estos males; En una palabra se demostrará por un lado, que el daño de los robos en la Corte es intolerable; Y se acreditará por otro, que el remedio de precaverle es legal, político y suave".

Tras referirse a la vida segura que se disfruta en los pueblos de corto vecindario (donde todos se conocen, las autoridades tienen prestigio y son obedecidas "Y donde, o bien la educcación, o, el recelo de ser fácilmente 
descubiertos" intimida y contiene a los potenciales delincuentes), sefiala D. Miguel que: "La civilidad, la mejor educación, el maior número de Sacerdotes, de Nobles, de Caballeros, y de Labradores, y la proporción de mejores arbitrios para vivir, y mantenerse, no son unas premisas que infieren la consecuencia de que allí será donde vivan todos seguros y mas tranquilamente? Pues la desgracia hace que desmienta en mucha parte la práctica, lo que la teoría persuade". Pensamiento que aplica a Madrd de la siguiente forma: "Quien no diría, que en el Vecindario más noble, $y$ distinguido de estos Reinos; en la Corte de Madrid, donde vive la Ymagen de Dios; donde tiene su asiento el Vicario del Seffor de los Ymperios; donde asiste el Centro de la Justicia; su Real Consejo, sus primeros Magistrados, y los más altos tribunales: se allaba tan sabiamente. coordinado, que no sentía el desasiego de los robos, y de los bullicios ninguno de sus abitantes? Pues a pesar de todo eso lloramos con resignación los excesos, y los latrocinios, que aunque minorados en el dia, han sido frecuentes antes, y se executaba cada instante".

El efecto de una delincuencia tan activa como la madrileffa deseja su huella en la población, según nos describe nuestro letrado: "Ninguno podŕa andar de noche seguramente confiado en algunas ocasiones, o, tiempos pesados, como lo haría en qualesquiera otro Pueblo limitado: Algunos se resguardan a fin de libertarse del recelo, y del sobresalto: Muchos se abstienen de ebacuar los asuntos urgentes: los más procuran precaberse: $\mathrm{Y}$ todos viven con la espina continua del cuidado: Yo no se como las gentes no reparan más atentamente en este universal, y perjudicialísmo dafio, u reunen todos sus esfuerzos para conseguir el fin de evitar-lo". Y redondea así su pensamiento: "Por que donde puede haber un mal en la República tan grave como el de vivir, y comunicarse los hombres con un recelo semejante? Yo no hallo en defecto tan sensible, como el que no gozen los Vecinos en qualquiera Pueblo del alivio de la tranquilidad y del sosiego: porque quien no ha de sobresaltarse al oir los insultos, las rapifias, y las muertes que se egecutan en Madrid, y aún en las demás Poblaziones grandes?"

Frases ilustradas seguidamente con la descripción de robos domiciliarios, atracos, asaltos, asesinatos, consecuencias de la prostitución ... para concluir que "Mucho más acertado es precaver que no haya Vagos, Bullicios, ni Ladrones, que tratar después de allados de castigarlos rigorosamente".

Para Ruano, "el maior mal que pueden padecer los hombres" es el motín o tumulto, pues los otros son particulares, afectan a un individuo o individuos en particular, mientras que el motín afecta a todos, es "común, y general a todos: Es la Epidemia Política que devora la justica, y el Gobierno con que se mantienen todos los abitantes de un Pueblo: Es el que 
imbierte la armonía, y trastorna todo el orden; Es la Guerra doméstica: y es el que produce los mismos efectos de combulsión, y desarreglo, en la Ciudad particular, y en el Estado, que los que causa el accidente de aplopegía en el Cuerpo humano; En ambos casos esta mui próxima la muerte, o la perdida de el Pueblo". Como ejemplo alude a las Comunidades, pero comenta un caso más reciente del que fue testigo: el motín contra Esquilache, sobre el que no aporta nada nuevo, pues más que entrar en el relato en sí del mismo, se entrega a consideraciones que nacen de su actitud radicalmente contraria al tumulto o a la asonada con la multitud furiosa y descontrolada como protagonista, lo que le lleva al punto que enlaza con el origen de su exposición:

"La multitud inordinada de Abitantes, y Vecinos; el abuso de devenirse a la Corte todos los buenos, y malos que quisieren sin limitación, sin examen ni escrutinio: el perjuicio de considerarla los Vagos, los mui infelizes, los enemigos del trabajo, y algunos Fazinerosos por refugio común, y por asilo. Los desarreglos del lujo; y la falta de distribución general, o, sobra confusión, y de laberinto, son ciertamente las Causas que producen los males que quedan referidos.

En Madrid sobran muchos hombres, muchísimas mugeres, y un sin número de todo genero de oficios. Y en el Reino, y los Lugares faltan Artífices, y trabajadores, si es cierto el defecto de Población que dicen nuestros políticos: En la Corte abundan los grandes empleos, las muchas ventas, y dinero, las demasias, el Luxo, y la duplicación de oficios: $Y$ en lo restante del reino se hallan minorados todos estos destinos".

La razón de tal afluencia de gentes y de los delitos que perpetran se explican por dos hechos: "La confianza de no ser allados: Y la esperanza de que. serán perdonados, son las dos ptes, qe. forman el todo de la causa original, o primaria qe. anima a los Ympios, y Ladrones a emprender los Bullicios, los robos, y las muertes, qe. no executarian a no proceder guiados de estas dos seguridades"./iTiene remedio la situación? Para nuestro D. Miguel sí y la propone en la segunda parte de su proyecto que lleva por título "Extremo Segundo. En que se explica el remedio ppco., y suave con que puede evitarse en la Corte los Bullizios, y todos los otros males".iCual es la solución? Así la aborda el Sr. Ruano: "el orden político es la única Ley, o, Medicina que ha dictado el Cielo para contener el impetu de los insultos que pueden cometer quantos componen qualesquiera Congregazion de Nazionales" y affade después: "La Sociedad, el orden civil, la Religión, el mantenimiento, la educación, y el travajo son la medicina de precaver los mayores vizios: y en su virtude se forma por este orden la extensión de los siguientes artículos"”

Dichos artículos se refieren: el primero a la Sociedad, donde aborda 
su origen y la condición sociable del individuo ("el origen de la Sociedad nace immediato de la naturaleza su Madre, y mediatamente de Dios que es su Criador, y como Padre"), con abundantes disgresiones jurídicas que le llevan a hablar del derecho divino y del natural, de las formas de gobierno - Democracia, Aristocracia y Monarquía -, de la defensa y de la policía: todo empedrado de citas de autores clásicos (Platón, Aristóteles), San Agustín, San Isidoro y "Santos Padres y Doctores".

El artículo segundo se refiere al orden público. Tras definirlo de varias formas (con variados apoyos que van de los clásicos a Hugo Grocio y Puffendor), lo precisa como la "reunión de Superiores e inferiores, constitutibos de Cuerpo formal, de Comunidad o República". En consonancia con esta afirmación, esta la relativa a la "sozialidad", sosteniendo que "es indispensable que los hombres vivan en companía y que esta subsista con la dirección que mas le agradase" y así, constituir la Ciudad y el Gobierno, dentro de la armonía general: "Como yo Juzgo que proviene de la confusión en le República la maior parte de los Daños: Y considero en el restablecimiento del mejor orden su principal remedio; me es inevitable la detención a fortificar las partes, o, extremos que constituyen el buen orden, o, Gobierno, para que salga tan firme el edificio, como las vasas que le sirven de Cimiento". Ello le da pie a extenderse de nuevo en consideraciones teórico-doctrinales, demonstrando nuevamente sus conocimientos y la variedad de autores que consulta (Sócrates, Licurgo, San Pablo y un ámplio etc.), imponiéndose en su discurrir las ideas de San Pablo sobre la diversidad de funciones, obediencia y sumisión al poder constituido, cuyo deber es velar por el bien general, para conluir: "Nada contribuye más eficazmente a mantener el Buen Orden en la Sociedad, como el establecimiento de Departamentos separados para cada ramo de Gobierno, y el que cada ramo, y cada administración tenga sus límites señalados".

La Religión es el tema del tercer artículo, redactado en el mismo tono docto que todo el trabajo. Las citas frecuentes a los Padres de la Iglesia, el recurso continuo a San Pablo, la exaltación del Creador en muchas ocasiones, permiten presumir el contenido de este capítulo y la importancia que da a la Religión, a la que califica de "alma de las Republicas", "el más firme apoyo del trono de un Soberano, y el freno más eficaz contra todos los delitos, y desórdenes que puedan perturbar el Estado" con un poder disuasorio superior al de cualquier pena corporal. El ataque a la impiedad y la defensa de la Cristiandad resultan totamente lógicos en este contexto.

En el artículo cuarto nos encontramos como tema el "mantenimiento", es decir la obligación del Estado de mantener y educar a sus ciudadanos, pues estos con su aplicación a un trabajo o actividad productiva con- 
tribuen al fortalecimiento de "la Republica. Cada uno de sus Abitantes que exerce oficio, u ocupación útil, la sirve como a su Señora, la reverenzia, como a su Madre, la respeta y obedeze como a Reyna, y como a Patrona la obsequia, la ensalza, y enriqueza: Con que razón será que en recompensa de todo esto, les atienda, y les alimente". Por tanto, deber fundamental del Estado es alimentar y vestir a todos sus componentes, modo de evitar la miseria, "mui destructiva para el Genero Humano. Es el origen de la demasiada continencia de los Vasallos Casados, de las Emigraciones, de las Enfermedades, Epidemias, de la multitud de Robos, y de otroa infinitos males que desvelan, y despueblan el Estado. Es pues preciso procurar que los Vasallos tengan de qe. vivir antes de pensar en hazer la Nación opulenta. La opulencia es el origen de todas las ventajas que constituyen a un pueblo feliz". Es en este punto donde interviene el trabajo, al que Ruano considera en un plano muy similar a la Religión: "Después de la Religion no hay freno que más detenga el impetu de las pasiones, como el de estar los hombres con utilidad ocupados". Y apostilla: "La ocupación continua y distribuida oportunamente entre todos los diferentes brazos de los Abitantes del Pueblo, es el movil que los alimenta, y el que mantiene el Estado". Nuevas citas de autores son traidas a colación para apoyo de tales afirmaciones, ilustradas también con ejemplos concretos que toma del inca Garcilaso de la Vega, referentes a la antigua civilización incaica.

El artículo cuarto se refiere a los robos y vagos. La primera nota a destacar es la confianza del autor en la prevención, tanto como en la represión: "que mejores son los medios de que no tengan necesidad de robar los hombres; que las Leies que tratan de Castigarlos rigorosamente". Hace a continuación una exposición de las principales ideas de los historiadores y jurisconsultos de renombre entonces (Antonio Terrason, Antonio Agustín, Próspero Farinacio, Arnoldo Vinio, etc.) para reflejar lo que se opinaba al respecto y ello le permite afirmar: "La proporción que deve encontrar-se entre la culpa y la pena, no tiene relación meramente a la materia del delito, sino al fin de gozar con quietud la vida común los Ciudadanos, y se mantenga com tranquilidad, y sin turbaziones la República". El apego de las gentes a la tierra los inclinará al trabajo y a hacer el bien, por lo que las posibilidades de delinquir y castigar disminuirán y en este sentido, propugna una norma de gobierno: apartar a "Olgazanes y Vagamundos de la República que no trabajan en ella", al tiempo que recomienda evitar los excesos y lujos: "Que se ponga mucho cuidado en el Reyno, y más, en la Corte porque de ella se derrama el bien, o, el mal a todo él, en Cercenar los excesos de los trages y gulas de los Banquetes, Comidas, de los Juegos y pasatiempos, de la liviandad, y libertad de las mugeres, de los gastos inmensos y excusados en las Dotes, Joyas, y atavios de ellas, y de ellos". 
Se centra después en cual debe ser actuación de la policia y como muestras ilustrativas recoge la de las grandes ciudades como Paris y, sobre todo, Londres. Respecto a lo que se espera de ella, senala: "Uno de los principales objetos de la Polícia consiste en evitar que la ciudad se halle infestada de Ladrones y vandidos. Nada arriesga más la seguridad pública que esta casta de gentes"; para cumplir con tal cometido, la policia debe estar informada de cuantos entran y salen de la misma, tanto naturales como extranjeros, visitar trimestralmente las casas de alojamiento de todo tipo e inspeccionar anualmente las casas de su cuartel para levantar una especie de censo o padrón. Todo lo cual facilitará una información preciosa para aplicar la pragmática de 1775 y eliminar a vagos y ociosos, cuya caracterización hace Ruano a tenor del contenido de la referida pragmática.

En el artículo sexto y último, que tiene por tenor "Reglamento gral. del Orden establezido", leemos en su comienzo: "Quanto hasta aquí se ha dicho prueba claramente que la Sociedad, el Orden, la Religión, las Leyes, la Enseffanza, y la ocupación, o, exercicio son los medios más propios de precaver, o, minorar todos los delitos: Sentados este principio se infiere: Lo primero: que según el arreglo de aquellos ramos, serán más, o, menos frecuentes, y maiores, y menos todos los Vicios publicos, y se deduce de esta ilación, o, correspondencia: Lo segundo, Que para evitar estos males, no hay mejor remedio que el conato de afinar, o, rectificar la práctica de aquellos". Y luego, entre ideas ya expuestas, hace una especie de repaso institucional no escatimando elogios ni alabanzas a la Milicia, a la Inquisición ("El Medio Santísimo que ha asegurado en la Nación Española el beneficio imponderable de la Unión de la Religión Católica, es el instituo del Santo Oficio de la Inquisición") y quiere implicar en el proceso tendente a mantener el orden establecido a Jefes, Gremios, padres, maestros y magistrados, un orden establecido que tiene una de sus bases fundamentales en "que se mantengan iguales la Valanza de las Personas y oficios que han de vivir en las Ciudades y en este Pueblo". Y como en Madrid están de más muchos en hacen falta en sus lugares de origen o destino, D. Miguel propone que se les obligue a salir, medida que debe afectar a todos, incluida la nobleza: "Y no se hade comenzar, como en lo pasado por la gente común, y vulgar; que para que esta salga, el medio que se pondrá, es el más eficaz, y relevante: y sería iniquidad dexar a los ricos, y poderosos que son los que han de dar sustento a los pobres ... Los que deven salir, son los Grandes y Seffores, y los Caballeros y gente de esta calidad, y un número grande que hay de Viudas mui ricas, y mui poderosas, y otras no lo son tanto, y se han venido a la Corte sin causa legitima ... y muchas personas Eccas. que teniendo obligación de residir en sus beneficios, so color de que tienen pleitos en esta Corte, y que sus Iglesias los envian a la defensa de ellos, se 
vienen a ella". Señalar igualmente "que en Madrid abundan los Grandes, los Señores, los Eccos., los togados y los militares" no encerraba ninguna novedad, pues era una realidad constatada largo tiempo, incluso en el siglo XVII, como el mismo Ruano refiere al poner puntualmente en notas nombres como los de Navarrete, Saavedra, etc.

Tan larga exposición - a veces farragosa, a veces con disgresiones, con frecuencia nada original - se cierra con un párrafo que la compendia (el autor lo escribe con esa intención): "el remedio de evitar, o, minorar los excesos ppos. en la Corte consiste en reducir el número de Vecinos; en expurgarla de los oziosos, prófugos, infelizes, y de los que carezen de ocupación y destino: y en disponer que no haya a qn. le falte el trabajo, ni el alimento indispensable: y en confiar la primera inspección económica a los Gremios de este Pueblo para que imiten la misma vigilancia y subordinación, y Govierno, que tienen todos los Reximientos, y Escuadrones de que se constituye el Exercito".

El "Resumen de los Medios suaves, y efectivos de precaver a Madrid del mal de los robos y demás Delitos” que D. Miguel añade á continuación de su exposición, se compone de veinte puntos, en donde con medidas ya apuntadas en su exposición, se incorporan otras o se matiza algo de lo ya dicho. Lo más destacable, a nuestro juicio, es lo que pretende conseguir de los Gremios y la institución a la que se encomendaría todo el ramo. Respecto a lo primero, en el artículo doce, leemos: "Ningún establecimiento habría más útil que el de elegir cada Gremio dos, o, más Fiscales, Celadores, Alcaldes, Caporales, o, Vehedores que fuesen bien quistos, de alguna antiguedad, y azenados en su oficio, para velar sobre la conducta de los demás Yndividuos por Centurias, por el orden que más les agradase, o, por el que en otras partes se halla establecido", las personas designadas para estos cargos sería conveniente que permaneciesen "muchos años" en los cargos, para su mejor rendimiento y se le atribuirían unas funciones, en gran parte, iguales a los de los Alcaldes de Barrio.

En cuanto a la responsabilidad del funcionamiento de todo el aparato, escribe D. Miguel en el artículo décimo séptimo: "Para la observancia exacta de todos estos ramos, sería necesario crear una Magistratura entresacada de Ministros del Supremo Consejo de Castilla, de la Sala de Alcalde de Casa y Corte, del Corregidor, Curas Párrocos, y Ayuntamiento de Madrid, que son las Comunidades en que reside en el dia esta vigilancia".

El expediente se cierra con un Apéndice para abordar el problema del excesso de mendigos en las ciudades grandes, incluida Madrid, "con respeto a lo que han indicado las Leyes, y los Autores, mucho antes", cuestión en la que nuevamente Ruano da rienda suelta a su erudición, cayendo en los mismos extremos que al principio de su trabajo. En realidad, poco 
hay de original en estas últimas páginas. D. Miguel calcula el número de mendigos (falsos y reales o fingidos y verdaderos) en unos setenta u ochenta mil, entre hombres, mujeres, ancianos y niños y al hilo de testimonios, casos particulares que han llegado a su conocimiento y dispsiciones oficiales, propugna aclarar la verdadera razón de la mendicidad de cada individuo (para lo que sería muy útil una especie de pasaporte); emplear a los fingidos o recuperables en ocupaciones apropiadas a su condición, sexo y aptitud y crear unas casas albergues para alojar a los verdaderamente necesitados, casas que se mantendrían con donativos y limosnas de particulares, cabildos y prelados.

\section{Plan de D. Valentín Melendo Gómez}

Nuestro nuevo personaje era abogado del Colegio de Madrid, enterado de que por Jubilación de su actual titular se va a producir la vacante, pide el 14 de julio de 1783 se le tenga presente para la provisión de la Fiscalía General de Obras Pias y de la Real Junta General de Caridad de la Corte. Como "contrapartida" ofrece tres proyectos, uno "sobre el medio, justo y completo, de socorrer a todos los Pobres de Espafia paqe. no haia mendigos, ni aún necesitados" socorro debido a todos los Pobres de todos los Reynos de España"6 y el tercero, referente al acondicionamiento de la Plaza Mayor de Madrid. ${ }^{7}$ Vamos a dejar a un lado el primero y el segundo, pues su carácter general y la amplitud del problema abordado nos llevaría muy lejos de nuestro objetivo. En cambio, el tercero si nos interesa por los detalles que ofrece de la vida madrileña y como exponente de un intento de ordenación urbana.

Tras aludir a trabajos anteriores realizados por él sobre la mendici$\mathrm{dad}$, declara que su intención con el presente proyecto no es desmerecer a nadie, sino hacer "presente, que la Policia . . . no consiste en mantener siempre en estado a las cosas, ni en darles nuevo, ni en mudarlas; sino en que todas tengan el más acomodado al uso Público". A continuación se refiere a la situación existente en a Plaza Mayor, lugar donde practican su negocio muchos vendedores, algunos con sus casas allí abiertas, pero otros vendiendo al aire libre, con lo que la lluvia les crea no pocos problemas, "con sus cosas esperando quien las compre, y en todo tiempo padecer con ellos, como los otros muchos males; derritiéndoseles el queso, y marchitándoseles y ennegreciéndoseles las Carnes y Pescados frescos con el Sol; comiéndoseles y ensuciándolo las Moscas; y esso y lo demás, pegándoseles tierra y basura, casi a todas horas". 
La situación no parece fácil de resolver, pues ya se habían confeccionado una serie de cajones para que metieran dentro los géneros y preservarlos algo, pero esos cajones eran insuficientes, aparte de que ya han ocupado la tercera parte de la plaza. El otro recurso que se apunta y que alguno ya ha ensayado consiste en poner mostradores y toldos, tiene para nuestro abogado los mismos o más inconvenientes que el de los cajones, pues obligaría a utilizar con este fin la mayor parte o la totalidad de la superficie de la Plaza, convirtiéndose esta en "un Quadro de Tiendas de tablas con las precisas Calles y entradas en medio de la Corte".

D. Valentín propone "que, quantos Tableros y Toldos y Caxones oi tiene, se echen fuera de ella, y tomando no más que tres baras por su circunferencia confin con sus Portales: se les corte este espacio con una Cortina de 9 palmos de altura toda ella, dejándola libres sus salidas a las calle . . ; de cuios 9 palmos el 1 o sea de piedra continuada del ancho de un Ladrillo para salvarlos de las humedades de el suelo, y los demás de tableros de madera, correspondientes en su largo a el ancho del Arco de cada un Portal de Luz, con uno de sus Postes, y divididos por su largo en dos partes con respecto a que por una de ellas se entre y salga a esse espacio, y por alto en tres, 1 a de tres palmos de altura, 2 a de Tercia de los cinco, y 3 a de los demás, assidas todas entre sí, y las dos últimas en disposición de doblarse azia la Plaza: se pongan Postecitos de piedra por todo el suelo de la circunferencia que la quede, con el repartimiento, altura, anchura, e inmediación correspondiente a que la $2^{\text {a }}$ parte de cada tablero pueda sentar sus dos extremos y la de cada compañero su contiguo sobre dos de ellos en llano igual a el alto de su 1ạ y la 3ạ ocultarlos haciendo un Rodapiés igual por la circunferencia de la plaza: y desde una a otra esquina de cada dos Partes de los portales la más interior de ellos, se eche otra cortina toda de Tablas, dividida como la de la Plaza, pero con respeto a que con el alto que tenga más el suelo de sus Portales, corresponda su $1^{\text {a }}$ en altura igual con la de la Plaza, y las restantes doblen acial el encajonado para que con unos pies de madera de el alto de su $1^{\text {a }}$ dentro, puedan servir como los de la Plaza y no embarazen en los Portales: y todo se cubre por el Cielo con tabla; en forma de un solo tablero desde el canto 1 o de los Postes a la Plaza, con el ancho de una tercia de cinco palmos fuera de su cortina, cubierto de Pizarra; y con vertiente a los Portales desde allí, sin ella: los pesos se cuelguen de los sobres de las Cortinas: la Caxa se divida por dentro correspondientea el largo de cada qual de estos: y toda se cierre, poniéndola sus cerraduras a los sobres y alto de las Cortinas, a los de la Plaza por Plaza y a los de los Portales por dentro de la Caxa".

Con esta nueva - y costosa - distribución de los vendedores y sus puestos, D. Valentín espera recuperar para el público mucho de espacio en- 
tonces convertido en mercado, facilitar el acceso a la plaza y hacer más fácil el pasear o deambular por ella, mayor seguridad para los comerciantes, que podrán guardar sus artículos sin tener que llevarselos por la noche para traerlos al dia siguiente. Tampoco se perjudicaría a las tiendas fijas de los portales, pues recibirían luz directa de la plaza por encima de los tejados de las de madera y además estaban situados más arriba de la altura a la que se colocaban los nuevos. El plan se cerraba con un "remedio" para el Peso Real, sito en la plaza y a todas luces insuficiente para atender al público: "Y por lo que hace a el Peso Real, el medio se reduce: a que sus siete Puestos se saquen a los siete Arcos de la Fachada de sus Portales por su Meridional, correspondientes recto a ellos, y se hagan, y pongan quatro más, dos a cada uno de sus lados ... con que se le dará como 8 pases por este su Quadrilongo" y vendría a alinearse con todo lo demás y solo se tendría que hacer modificaciones en su disposiciń (cambio de puertas y ventanas) para que se adaptara a la nueva disposición.

En definitiva, D. Valentín aspira a darle un uso más racional para el marcado al recinto de la Plaza Mayor, pero la reforma que proponía resultaba costosa y suscitaría las inevitables protestas si se intentaba aplicar.

\section{Ideas de D. Mariano Martínez González}

El autor del proyecto que ahora nos va a ocupar, había sodo veedor fiscal y visitador general del Canal Real del Reino de Murcia, avecinado en Madrid, se había presentado en dos ocasiones a Floridablanca solicitando un destino y este le contestó que se enteresase de "vacante fixa y la pretendiera". Por más que D. Mariano buscó, no encontró nada y decidiose entonces a presentarle un proyecto "para que las alajas, y de más cosas que diariamte. se pierden en Madrid, se hallen con facilidad quasi todas, o, la mayor parte, y se restituyan a sus legítimos dueños". ${ }^{8}$ En apoyo de su plan, Martínez González comenta: "Madrid, es un Pueblo Basto, en donde cada dia se pierden dineros, alajas, papeles, y otras cosas, cuyo valor annual asciende a muchos miles rs.: la restituzon. no se puede verificar, por que, aun cuando los sugetos que hallen las alajas, etc. sean timoratos, como ignoran sus dueños, $\mathrm{y}$ no tienen la más remota noticia, se quedan en buena conciencia con ellas; sucediendo alguna vez, que el que perdió la alaja, fixa papeles en parages públicos, y llegando por casualidad a saberse, hay alguna restituzon., que se mira como milagro".

El proyecto de D. Mariano consiste, sencillamente, en establecer una casa en Madrid, "denominada $=$ Casa Depósito de dineros, alajas, papeles, y demás que se pierden". A dicha casa iría el que hubiera perdido alguna co- 
sa para dar su descripción puntual, que se registrará en un libro, anotándose al margen la restitución, cuando se produzca, " $\mathrm{y}$ el tanto que voluntariamente diere el Dueño de gratificazión; quien dejará recibo de habersela llevado". Igualmente, el que encuentre algún objeto, deberá notificarlo a la Casa del Depósito en un plano de 48 horas "y si por alguna casualidad se verificase tenerla en su poder, sin aquella diligencia, se tratará como robo"; este plazo se amplía a 8 dias para los hallazgos que tengan lugar en los $\mathrm{Si}$ tios Reales o Caminos. La citada Casa deberá estar situada "en parage público, para cuyo alquiler, y alguna ayuda de Costa al Depositario, y su familia, se le asignará anualmente la cantidad que pareciere". El Depositario o Interventor estará obligado a llevar puntual cuenta de las alhajas que se han entregado, de las devoluciones y de la existencia que queda para poder dar cuenta de todo en cualquier momento y entregar anualmente una memoria. La financiación del establecimiento y personal del mismo se atendería, además de los dicho, repartiendo el importe de las gratificaciones voluntarias en tres partes: dos para el que encontró el objeto perdido "y la otra al Depositario para ayuda a los gastos de escritorio, y tal vez manuttenzon. de un Ayudante que asista, pues con este motivo será mucha la concurrencía, aún con la nota de la cosa más mínima". Tanto fiaba D. Mariano en los buenos efectos de su plan que afirma: "con el motivo dela Casa Depósito, podrá suceder muchas vezes, que algunas alajas robadas se lleven a ella, porque los Agresores, arrepentidos del delito excogiten este medio, y por una corta gratificazon. se encuentren los Dueffos con sus alajas".

Por supuesto, en su instancia, suplica a Floridablanca "se sirva admitirle y nombrar al Exppte. por depositario como Interventor de él, con las demás providencias q. fuesen de su agrado".

Pero D. Mariano - según todas las trazas - tendría que seguir buscando vacante para su colocación.

\section{Proyecto de D. Pedro Eduardo Vélez}

Natural y Regidor perpetuo de Alcántara (Extremadura), D. Pedro Eduardo Vélez presenta al rey un proyecto ${ }^{9}$, al que "ha dirigido su desvelo de muchos affos", destinado "a proporcionar un medio conque pueda vivirse en la Corte sin aquel rezelo que ocacionan los Alborotos, robos, y escándalos, y demas que produze el conjunto de tantas Gentes en una Pa- 
tria Común". El regidor dice haber encontrado ese medio y "se anima a ofrezer a V.M. baxo quatro capítulos, la obligación siguiente:"

En el primer capítulo sostiene que limpiará la Corte sin necesidad de recurrir a las levas "que solo sirven para ocasionar molestias a los Ministros de V.M. y sonrrojo y demás cuando charlan después del trabajo, buscando un rato de entretenimiento, y que son detenidas hasta que se aclara su identidad, cosa que a veces no es posible y son destinados al ejército, presidios o arsenales. Em cambio, "siempre vienen a quedar libres los Bagos verdaderos, que viven de jugar, y hurtar, en borracheras, amanzevamientos, y demás; como que estos, por varias razones, saven dias antes que se publique la Leva, que ha de salir, y procuran ponerse a salvo interin dura".

En el segundo capítulo, el autor ofrece algo que interesaría mucho a la Corona: "Asegurar a Madrid de Alborotos, y Robos, de modo, que en qualesquiera ora del dia, o noche, que se de alguno, será cortado: $Y$ de estos, aprehendido el Delincuente o Delincuentes, sobre el hecho, sin arbitrio a la fuga"; como contraste a su oferya, señala que la mayor parte de los detenidos por los Alcaldes de Casa y Corte "no son sugetos que por su trage llevan la recomendación de sospechosos, antes si, les salva la decencia para desvanecer qualquiera sospecha, en quien les encuentra . . . Y es dificilísir. 0 descubrir esta clase de Personas, (no cogiéndolas en el hecho) sino es por medio del establecimiento que se desea entablar".

El tercero nos ofrece datos sobre el comportamiento de ciertos individuos. Lo recogeremos literalmente: "Quitaría enteramente un Crecido número de Personas que viven con la maior ostinación del juego, robando qunto dinero se les presenta en la Mesa, usando para ello de las más diabólicas fullerías, imperceptibles golpes de mano, e imperceptibles marcas en las Cartas y cargas en los Dados y Tavas; y tan asegurados se hallan con estas havilidades que no solo andan en la Corte vigilando quantos forasteros viene a ella, para ver el modo como por sí, o por Ganchos logran jugar con ellos; sino que tienen exacta razón de quantas Ferias, y funciones señaladas, ay en el Reyno a todas concurren, con pretexto de fingrise Mercaderes, cumplir promesas, y otros que les facilita el ardid, para dejar perdidos a muchos, y ellos bolberse a la Corte a gastar lo que roban".

El cuarto capítulo incide en otra cuestión que venía preocupando a las autoridades y ofrece recoger en las Casas del Hospicio y San Fernando "mucha clase de mugeres, y hombres perjudiciales en la República (auqe. sea precisa la tolerancia de otras de aquellas, por oviar mayores dafios, tratando solo de los que deban custodiarse por escandalosos, y amanzevados, dando lugar a que en las Casas tengan los Matrimonios continuos desazones) arbitrando medios capazes, no solo de amantenerlos en ellas, sino para poner sus Fábricas en un estado respetable, entre las demás de su clase". 
El autor se ofrece a llevar a término su plan en el plazo "de un año, asegurándolo asistir con su persona, siempre que no le falte a quanto pide en los Capítulos que Cierran esta representación; sin que por aora, y hasta estar verificado el arreglo, y establecimiento, pida para sí señalamiento de sueldo; y entonces, lo reserva a la voluntad de V.M.". Como aval de la conveniencia de su plan, "se hacen demostrables los beneficios que al pronto resultarán, deseando en solenciar otros, que con el tiempo se propondrán a V.M. para su aprobación, no demenos importancia y utilidad".

Los beneficios que sefala D. Pedro Eduardo Vélez que se alcanzarían, no son ni más ni menos que el de muchas de las pragmaticas emitidas por el Gobierno, si se cumplieran, para una mayor seguridad en la Corte. Este es, precisamente, el primero que destaca el personaje que nos ocupa: "Tendrá V.M. su Corte sin la menor alteración, y sus Vasallos seguros en ella, para poderse conducir por donde la necesidad los llame sin riesgo de ser acometidos por rateros, o Ladrones que los degen, sin quanto llevan consigo". Igualmente se podrán incrementar los ejércitos con centenares de hombres anualmente, con los hombres útiles "que siempre se reservam de este destino por más Levas qe. haya". Disminuirían también "los Asesinos, que con Capa de Honrradez", ganan el dinero a "muchos viciosos", por medio de "fullerias, dexándolos perdidos, y a V.M. con aquellos vasallos menos para la Contribución". Asimismo, aumentarán su producción las fábricas del Hospicio y San Fernando, "empleándose en ellas, no solamente la Gente que de Madrid, y sus cinco Leguas recoja, sino mucha parte de la pobreza del Reyno, que acosta de ser mendigos, circula por el sin Domicilio seguro". Con todo ello, el trabajo de los Alcaldes de Corte se aliviaría bastante y podrían "atender el despacho de otros asuntos". Por último, propone el autor la construcción de un Colegio - en un plazo de dos o tres affos - para enseñar Naútica "a los muchachos que se recojan en él", para que puedan servir en la Marina.

La parte final del proyecto ${ }^{10}$ esta encaminada a garantizar lo ofrecido anteriormente. Es lo que podemos considerar la parte técnica del plan, pues en ella nos enteramos de cual es el remedio que D. Pedro Eduardo Vélez ha descubierto después de mucho tiempo de cavilaciones. También nos da las claves personales de su proyecto, pero no olvidemos que se ofreció para llevar a la práctica su propuesta. En definitiva, lo que porpone es crear el cargo de Celador de Madrid y sus cinco leguas con "jurisdicción omnimoda para que por falta de ella, no padezcan demora algunas prontas providencias que los casos requieran". Los Alcaldes de barrio dependerían directamente de él, quien por su parte, "ha de estar independiente de los Alcaldes de Casa y Corte, Corregidor, y sus Thenientes", intercambiándose todos información por escrito. Su capacidad resolutiva solo requeriría la 
intervención de una especie de supervisior: "Ha de nombrarse por V.M. un Ministro del Real Consexo de Castilla, Juez de esta Comisión, para que intervenga en todos los Yncidentes concernientes a ella; Pero en las causas, solo tendrá la facultad de ver las sentencias (dadas con acuerdo del Asesor) y minorarlas o agravarlas, según le parezca ser justo, de modo, que aprovada por el la Sentencia, se ha de observar imbiolablemente".

Será preciso emplear algunos individuos en el desempeño y desarrollo de las funciones que competen al Celador, al Juez, al Asesor Escrivano y al Tesorero, cuyos sueldos y los de los demás dependientes se fijarán por el Juez y el Celador y abonará el Tesorero, "en virtud de nomina firmada del Celador con el visto bueno del Juez".

En cuanto a su actuación, se piensa en la misma línea expeditiva que apunta en la autonomía e independencia del cargo de Celador: "Que haya de poder entrar en qualquiera parte, a la ora que el caso requiera, sin más orden que la de su Jurisdición; siempre, y quando que se halle asegurado, de haver Juntas, Juegos prohividos, u otro motivo"; además, si es preciso, "se les dara auxilio quando que lo pida, por las Justicias, Militar y Política".

La financiación de esta novedad institucional se hará por medio de $\nvdash\urcorner$ procedimiento muy frecuente en la época: "se le ha de permitir Lizencia de quatro dias del año, en los quales puedan correrse otras tantas funciones de Novillos, en la Plaza Cerrada de la Puerta de Alcala, sin que los Hospitales tengan en ella intervención alguna, respecto a ser su producto para el beneficio Común, y que se harán en Ymbierno, para que no se le perjudique a sus funciones, presidirá el Corregidor, o su theniente, y se dispondrán por el Celador con intervención del Juez y Thesorero”. El dinero que así se recaude como el que se reuna por otros procedimientos aplicados a gastos de esa dependencia, será manejado por el tesorero, nombrado a propuesta del Celador con aprobación del Juez. El tesorero dará cuenta anual del movimiento de dinero habido, entrante, saliente y existente, empleándose este último - si lo hay - en lo que el Rey decidaa consulta del Celador, "por mano del Juez".

El proyecto no lleva fecha y no podemos datarlo con precisión, pero todo hace presumir que es anterior a 1782, affo en que se crea la Superintencia General de Policia, instituición que D. Pedro no nombra. En cualquier caso, esta iniciativa - de indudable alcance - tampoco prosperaría. 


\section{A manera de eprlogo}

Para finalizar estas páginas nos vamos a detener en unas consideraciones, nacidas al hilo de la lectura y reflexión de los testimonios que anteceden. En primer lugar, nos parece que la afluencia de proyectos (de los que nosotros presentamos un ligero muestreo, en espera de una ocasión que nos permita un estudio más profundo sobre un mayor número de ejemplos) refleja un estado de ánimo existente en un sector social minoritario, pero cualificado, estado de ánimo que nos parece reflejo del eco despertado por las directrices gubernamentales, a lo que no le resta valor el hecho de que los autores de los planes se conviertan en parte interesada en su realización práctica - cosa lógica, por demás - al solicitar como contrapartida a las excelencias de su exposición, un puesto remunerado en la administración.

No deja de ser menos sintomático que ninguno de los firmantes esté vinculado directamente (en "activo", diriamos hoy) al ramo que pretende mejorar. Eso tiene dos consecuencias que marcan la suerte futura de los proyectos: por un lado, no estan al tanto de las preocupaciones gubernamentales al respecto y desconocen si en los momentos en que ellos hacen su oferta, se trabaja en el tema en instancias superiores y si es así, cuales son las directrices que se siguen; por eso, se mueven en el terreno marcado por las pragmáticas o bandos promulgados y ello se traduce en una visión "tradicional y conservadora" del problema que la hace poco atrayente para el gobierno. Por otro lado, los autores de los proyectos desconocen las verdaderas posibilidades de acción de las personas a las que los presentan y van a ofrecerles algo en un ramo en el que se ha trabajado o se está trabajando con mejoras tan escasas o costosas que no dejan incidencia alguna en las directrices seguidas por la superioridad y, a veces, su oferta es tan poco sustancial que no llega a destacarse en el conjunto de mayor envergadura que preocupa al gobierno, por lo que son descartados de antemano. El silencio generalizado que sigue a la presentación de estos planes es un indicador muy válido para deducir el eco despertado en las esferas gubernamentales.

Y por debajo de todo, nos parece que existe una preocupación no menos generalizada: la preocupación por la "gran ciudad", cuya oferta cultural, de trabajo y diversión actúa como poderoso reclamo sobre las gentes, que se trasladan a ella con los consiguientes problemas que la afluencia de población genera y que obliga a las autoridades a extremas el control y prevenir soluciones a problemas que se palpan o se intuyen. Tal vez, en esto 
radique la mayor novedad de cuanto antecede y en esto si pudieron resultar premonitorios los planes vistos, pues el progreso del urbanismo va a obligar a los responsables del gobierno ciudadano a encarar con nuevas ópticas los problemas de abastos, ordenamiento cívico, seguridad, etc., cuestiones que resultarán ineludibles en el siglo siguiente y que desde entonces marcan permanentemente el pulso vital de la gran urbe.

\section{NOTAS}

${ }^{1}$ Estos planes y proyectos estan diseminados por los legajos de la Sección de Estado del Archivo Histórico Nacional de Madrid (A.H.N.), aunque de cuando en cuando se encuentran algunos de ellos reunidos. En este sentido, el legajo 30332 es un buen hallazgo, ya que todos los que hemos citado y otros que omitimos sobre redención de censos, caminos, hospicios, etc. se encuentran en él. Algunos resultan especialmente interesantes por los altos objetivos a que aspiran, como ocurre con los contenidos en los legajos 31712,31802 y 3181 .

De su lectura se desprende algo que apuntabamos antes: el deseo generalizado entre los firmantes y la petición consiguiente de que se les tenga en cuenta para algún puesto de la Administración pública y, en ocasiones, ese puesto que desean está en relación con el proyecto cuya autoría les corresponde.

${ }^{2}$ Vid. el dossier dedicado a los incendios contenido en el Leg. 31712.

${ }^{3}$ Véase MARTINEZ RUIZ, E.: "Las fuerzas de seguridad y orden público en la primera mitad del siglo XIX”, en Cuadernos de Historia, t. IV, 1973, págs. 83 y ss.

${ }^{4}$ Manuscrito en tamaño folio y numerados los pliegos correlativamente hasta el 33 ; a partir de él sigue un "Resumen de los Medios, suaves, y efectivos de precaver a Madrid del mal de los robos y demás delitos" y un apéndice para "reformar en Madrid y demás poblaciones grandes el exceso de Mendigos", también en folios numerados con independencia de los anteriores, del 1 al 7. A.H.N., Estado, leg. 3016. En este, como en todos los demás proyectos, respetamos la grafía original sin otra indicación en este sentido.

${ }^{5}$ Como los otros dos, va escrito en folio; esta fechado el 14 de diciembre de 1781 y ampliado con nuevos datos el 13 de marzo de 1783. A.H.N., Estado, leg. 30332.

${ }^{6}$ Cosido al anterior, tiene como data 22 de mayo de 1782 .

${ }^{7}$ Más breve que los anteriores, el autor lo envia al rey el 20 de enero de 1784 .

${ }^{8}$ Exposición a Floridablanca, fechada en Madrid a 11 de enero de 1785 . Le acompaña el plan (a cuyo título corresponde el entrecomillado), distribuido en nueve puntos. A.H.N. Estado, leg. 3016.

${ }^{9}$ No lleva fecha ni otra indicación que nos permita situar aproximadamente el momento en que se presentó. Por las expresiones y términos que emplea, pensamos que es del reinado de Carlos III, en un momento en que predominarían las preocupacio- 
nes por limpiar la Corte. Leg. 3016.

${ }^{10}$ Todo el proyecto va redactado en tres pliegos. Tiene, por tanto, 12 páginas de tamaño folio. Las cuatro últimas destinadas a exponer las condiciones necesarias para llevar a efecto el plan.

* Facultad de Geografía e Historia Universidad Complutense de Madrid 28040 - Madrid - España. 